\title{
EFEITOS DA MULTIPARENTALIDADE NO DIREITO DE FAMÍLIA
}

\author{
EFFECTS OF MULTIPARENTALITY ON FAMILY LAW
}

Fabíola Albuquerque Lobo ${ }^{1}$

\section{RESUMO}

O presente artigo tem por finalidade analisar o instituto da multiparentalidade e seus efeitos no direito de família. Como sabido, o ingresso da multiparentalidade, pela via jurisprudencial, se deu com o julgamento do tema de Repercussão Geral 622, representado pelo leading case RE 898060, cujo julgamento resultou no reconhecimento jurídico do vínculo de fíliação socioafetivo e biológico concomitantes. Diante da complexidade que envolve a multiparentalidade, se faz necessário a fixação de limites quanto a sua aplicação, por sua vez, balizados pelo princípio do melhor interesse. A multiparentalidade necessariamente exige uma interlocução prévia com a socioafetividade, pois enquanto àquela é recente, esta possui elaboração teórica e aplicação prática consolidadas no direito brasileiro.

Palavras-chave: multiparentalidade; princípios constitucionais; socioafetividade; família.

\section{ABSTRACT}

This article aims to analyze the institute of multiparenthood and its effects on family law. As is known, the entry of multiparenting, through jurisprudence, took place with the judgment of the topic of General Repercussion 622, represented by the leading case RE 898060, whose judgment resulted in the legal recognition of the concomitant socio-affective and biological affiliation. Given the complexity that involves multiparenting, it is necessary to set limits on its application, in turn, guided by the principle of best interest. Multiparenthood necessarily requires a prior dialogue with socio-affectiveness, because while the former is recent, it has theoretical elaboration and practical application consolidated in Brazilian law.

Keywords: multiparenting; constitutional principle; sociafectivity; family.

\section{INTRODUÇÃO}

A Constituição Federal de 1988 instituiu intensas e inúmeras transformações ao direito de família. Esse cenário de quebra de paradigmas, contempla um dos maiores desafios que é à apreensão da afetividade enquanto princípio jurídico e sua compreensão enquanto essência e fundamento das relações familiares.

A natureza socioafetiva do parentesco transformou sobremaneira o significado e a dimensão da filiação no direito brasileiro, ao mesmo tempo que impulsionou doutrina e jurisprudência a darem um "giro copernicano" no enfrentamento desta nova realidade. O critério jurídico da socioafetividade foi posteriormente acolhido pelo Código Civil/2002, ao dispor que o parentesco é natural ou civil, conforme resulte de consanguinidade ou outra origem (art. 1593). Neste sentido temos a filiação biológica ladeada pela filiação socioafetiva, a qual, por sua vez, se materializa nas seguintes espécies, quais sejam: filiação proveniente da adoção, filiação

\footnotetext{
${ }^{1}$ Professora Titular de Direito Civil do Centro de Ciências Jurídicas da UFPE. Doutora em Direito Civil pela UFPE. Professora do PPGD/UFPE. Vice-líder do Grupo de Pesquisa Constitucionalização das Relações Privadas (CONREP/UFPE/CNPq).
} 


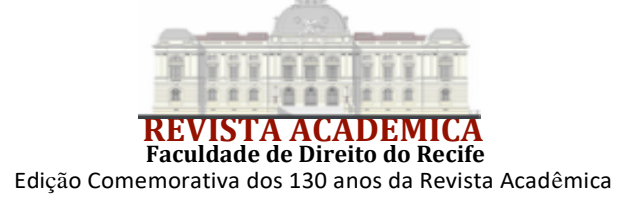

proveniente das técnicas de reprodução assistida heteróloga e a filiação proveniente da posse de estado.

Importante ressaltar, que a elaboração teórica em torno da filiação socioafetiva, remonta ao final da década de 1970, com o revolucionário artigo, de autoria de João Baptista Villela, intitulado "Desbiologização da paternidade"2. Posteriormente, vários outros autores se debruçaram sobre o tema. O mesmo, se verificou na jurisprudência, mediante a aplicação prática da socioafetividade. Portanto, o reconhecimento jurídico da relação socioafetiva apresentava-se devidamente consolidada e reconhecida na doutrina e jurisprudência brasileiras.

A temática da socioafetividade bateu às portas do STF, sendo reconhecida a existência de repercussão geral da controvérsia relativa à prevalência ou não da paternidade socioafetiva em detrimento da paternidade biológica (Tema 622), cujo caso paradigma é representado pelo RE 898060/SC. Do julgamento resultou a fixação da seguinte Tese:

A paternidade socioafetiva, declarada ou não em registro público, não impede o reconhecimento do vínculo de filiação concomitante baseado na origem biológica, com os efeitos jurídicos próprios.

Indiscutivelmente, uma decisão surpreendente e inesperada, vez que inexistia qualquer discussão amadurecida sobre a multiparentalidade quer pela doutrina ou pela jurisprudência familiarista.

A compreensão do estado da arte da multiparentalidade pressupõe passar em revista alguns pressupostos, quais sejam: o estatuto jurídico da socioafetividade, a aplicação direta e imediata dos princípios constitucionais às relações privadas e, a superação do modelo binário das relações de parentalidade.

Desta nova realidade jurisprudencial extrai-se positivamente o reconhecimento da igualdade jurídica entre a parentalidade socioafetividade e a parentalidade biológica.

\section{CONTEXTUALIZAÇÃO FÁTICA DO CASO PARADIGMA}

Em 2003, F.G (19 anos) ingressou com ação de investigação de paternidade cumulada com a retificação de registro civil e a fixação de alimentos, em face de A.N.

Segundo historiou a autora, na petição inicial o suposto pai e a mãe de F.G se relacionaram por aproximadamente quatro anos. Durante este período S.G engravidou, mas foi abandonada por A.N. Neste ínterim S.G conheceu outro homem (I.G) e pouco tempo depois casaram-se. Quando do nascimento, a criança foi registrada como filha pelo marido da mãe. Durante 14 anos, esta realidade fez parte das vidas da filha e do pai, mas tal crença foi desfeita quando tomaram conhecimento, que na verdade F.G era filha biológica de A.N, o que foi constatado posteriormente com o resultado do exame de DNA.

Em $1^{\circ}$ grau, a magistrada constatou a existência e a permanência do vínculo socioafetivo entre F.G e I.G, mas a linha de fundamentação foi no sentido que a sobreposição da verdade socioafetiva à genética não se sustenta, porquanto "a descoberta posterior, em casos como o presente, acerca do vínculo biológico traz consigo a ciência da falsidade ideológica existente no registro público de nascimento." Desta forma julgou procedente o pedido formulado por F. G. de retificação de seu registro de nascimento, excluindo-se a paternidade de I. G. e incluindo-se a de A. N., além de determinar o pagamento pelo último de pensão alimentícia equivalente a quatro salários-mínimos mensais, desde a citação inicial até a conclusão do curso universitário pela demandante. $^{3}$

A.N (pai biológico) recorreu da decisão e a Quarta Câmara de Direito Civil do Tribunal de Justiça do Estado de Santa Catarina, por maioria de votos, deu parcial provimento à apelação. O Relator, no acórdão adotou entendimento oposto ao tomado pela instância monocrática. Vejamos

${ }^{2}$ revista.direito.ufmg.br/index.php/revista/issue/view/62

${ }^{3}$ Disponível em: stf.jus.br. STF. RE 898060. 


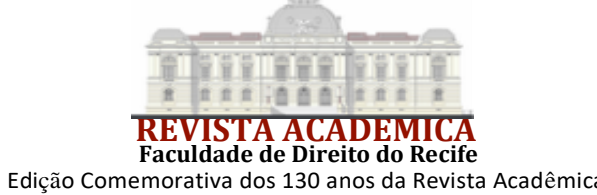

Edição Comemorativa dos 130 anos da Revista Acadêmica

uma parte da ementa:

O demandado é, de fato, pai biológico da postulante - mas, o estado de filiação resta consolidado entre esta e o pai registral, cuja posse do estado de filho se verifica desde o nascimento da registrada, o que torna a situação irreversível. Portanto, não deverá ser reconhecido em sede de ação investigatória, proposta pelo filho contra o suposto pai biológico. Há inclusive manifestação expressa por parte desses dois indivíduos, no sentido de que continuarão a se reconhecer como pai e filha independentemente do resultado do processo judicial - aspectos que conduzem a improcedência do pedido, quanto à alteração do registro civil de nascimento e condenação do recorrente ao pagamento de alimentos em favor da autora - provimento parcial do recurso, com a manutenção da sentença apenas no que tange à declaração de origem biológica da postulante. Na espécie, ainda, a flagrante rejeição e desinteresse do requerido em se relacionar com a autora mostra que o atendimento da pretensão por ela deduzida, neste particular, apenas poderia lhe conferir benefícios de ordem material, visto que a prestação de amor, carinho e afeto, esta não se pode impor àquele que, pela vontade própria, a recusa. ${ }^{4}$

F.G, inconformada com o julgamento, ingressou com Embargos Infringentes, os quais foram providos à unanimidade de votos, pelo Grupo de Câmaras de Direito Civil do Tribunal de Justiça do Estado de Santa Catarina, "para nos termos da sentença e do voto vencido declarar a paternidade de A.N em relação a F.G. Assentou o acordão que:

Direito à paternidade biológica. Exame de DNA positivo. Filiação comprovada. Paternidade registral-afetiva concedida em erro que não afasta o reconhecimento do vínculo genético, o qual gera, indubitavelmente, efeitos jurídicos relativos ao nome, alimentos e herança. Alteração do registro de nascimento. Reflexos patrimoniais inafastáveis. [...].

A.N irresignado, interpôs Recurso Extraordinário e F.G apresentou contrarrazões ao Recurso Extraordinário.

\section{FUNDAMENTOS DO VOTO CONDUTOR E DO VOTO DIVERGENTE}

Após minucioso relatório, o Ministro Relator Luiz Fux inicia seu voto localizando a filiação, como um dos elementos integrantes dos direitos da personalidade. No, caso dos autos cumpre definir os efeitos jurídicos da paternidade biológica, antecedida por um vínculo socioafetivo. A fundamentação do voto centra-se precipuamente no princípio da dignidade humana, no princípio do melhor interesse do descendente, no direito ao conhecimento da origem biológica e no princípio da paternidade responsável.

Nessa linha, o Ministro Relator constrói seu voto afirmando que: "é imperioso o reconhecimento, para todos os fins de direito, dos vínculos parentais de origem afetiva e biológica, a fim de prover a mais completa e adequada tutela aos sujeitos envolvidos". Nesta altura, apesar do Ministro Relator referenciar as diversas formas de parentesco, a igualdade entre eles e o princípio da afetividade, mas mostrava-se convencido que a solução mais apropriada para responsabilizar o pai biológico dos seus deveres parentais era mediante a aplicação da dupla paternidade.

Inaugurando a divergência de fundo, o Ministro Edson Fachin inicia seu voto demarcando que o caso concreto encontra resposta na normativa constitucional, em especial com o reconhecimento da igualdade jurídica da filiação, independente da origem (biológica ou socioafetiva). Se manifesta pela inexistência, no caso concreto, de um conflito de paternidade

De um lado, o vínculo socioafetivo consolidado no tempo, com os requisitos da posse de estado de filiação preenchidos e, de outro o vínculo biológico da autora, devidamente comprovado. Percebe-se que o voto é permeado pelo enaltecimento da relevância do princípio constitucional implícito da socioafetividade e seus impactos no direito de família brasileiro vanguardista,

${ }^{4}$ Disponível em: stf.jus.br. STF. RE 898060. 


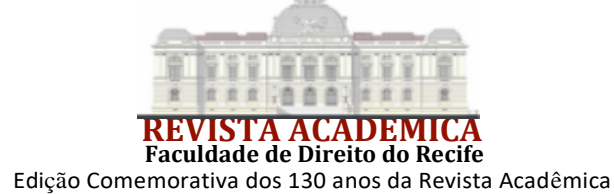

principiando com o reconhecimento jurídico do estado de filiação matizado, na mais genuína realidade afetiva relacional entre pai e filho. Situação que instiga o seguinte questionamento, por parte do Ministro: "qual espécie de vínculo tem a aptidão para determinar a relação parental"?

Neste primeiro momento, a reflexão do ministro visa estabelecer com precisão a necessária distinção entre estado de filiação e origem genética. Segundo ele, o estado de filiação enquanto categoria jurídica é aquele cuja aferição retrata uma situação relacional objetiva, pautada na riqueza e na realidade fática dos vínculos afetivos entre pais e filhos. Enquanto a origem genética diz respeito ao direito do filho de conhecer seus vínculos biológicos, na dimensão dos direitos da personalidade, a exemplo da adoção.

Se o vínculo socioafetivo antecede o vínculo biológico, este não deve prevalecer sobre àquele, em razão apenas de resultados genéticos. Sua incidência de dará, se não houver uma paternidade e um estado de filiação socioafetiva estabelecidos.

O Ministro ratifica a efetiva viabilidade jurídica da multiparentalidade, porém em caráter excepcional e dentro de parâmetros congruentes à realidade do caso concreto. Deste modo afirma que:

A multiparentalidade só pode ser reconhecida quando se expressa na realidade da socioafetividade (o pai biológico quer ser pai, o pai socioafetivo não quer deixar de sê-lo, e isso atende ao melhor interesse da criança - ou é consentido pelo adolescente.

Sem embargo, de multiparentalidade não se trata a hipótese contemplada no caso concreto, cuja solução encontra-se na necessária distinção entre estado de filiação e origem genética. ${ }^{5}$

\section{EFEITOS E PROBLEMAS DECORRENTES DA MULTIPARENTALIDADE}

- $\quad$ Reconhecimento jurídico que não há prevalência entre a paternidade socioafetiva e a biológica;

Em corroboração, trazemos à lume o recente julgado da $4^{\mathrm{a}}$ Turma do STJ.

Multiparentalidade. Pais biológico e socioafetivo. Efeitos patrimoniais e sucessórios. Tratamento jurídico diferenciado. Impossibilidade. Na multiparentalidade deve ser reconhecida a equivalência de tratamento e de efeitos jurídicos entre as paternidades biológica e socioafetiva. ${ }^{6}$

- $\quad$ A materialização do princípio da pluralidade das entidades familiares;

- Quebra da relação binária da paternidade para multiparentalidade.

Em princípio, a ideia que preside a multiparentalidade é de um instituto extraordinário, afinal feliz daquele que consta no seu registro de nascimento uma pluralidade de vínculos coexistentes. Mas, como sabemos nem tudo são flores e o cotidiano da multiparentalidade revela-se extremamente complexo.

Vejamos alguns problemas de ordem prática:

A quem caberá a tomada de decisões relativas ao exercício do poder familiar, segundo às hipóteses contempladas pelo art. 1634 do CC, na ambiência da multiparentalidade?

I - dirigir-lhes a criação e a educação; (Redação dada pela Lei no 13.058, de 2014)

III - conceder-lhes ou negar-lhes consentimento para casarem; (Redação dada pela Lei $\mathbf{n}^{\circ}$ 13.058, de 2014)

IV - conceder-lhes ou negar-lhes consentimento para viajarem ao exterior; (Redação dada pela Lei $\mathrm{n}^{\mathrm{o}} 13.058$, de 2014)

\footnotetext{
5 A propósito ver. LOBO, Paulo. Estado de filiação e origem genética: uma distinção necessária. https://ibdfam.org.br/artigos/126/Direito+ao+estado+de+filia\%C3\%A7\%C3\%A3o+e+direito+\%C3\%A0+origem +gen\%C3\%A9tica:+uma+distin\%C3\%A7\%C3\%A3o+necess\%C3\%A1ria.

6 STJ. REsp 1.487.596-MG, Rel. Min. Antonio Carlos Ferreira, Quarta Turma, por unanimidade, julgado em 28/09/2021, DJe, 01 out. 2021.
} 


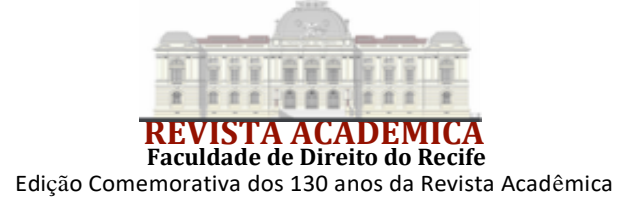

$\mathrm{V}$ - conceder-lhes ou negar-lhes consentimento para mudarem sua residência permanente para outro Município; (Redação dada pela Lei n ${ }^{\circ} 13.058$, de 2014)

VI - nomear-lhes tutor por testamento ou documento autêntico, se o outro dos pais não lhe sobreviver, ou o sobrevivo não puder exercer o poder familiar; (Redação dada pela Lei $n^{\circ}$ 13.058, de 2014)

VII - representá-los judicial e extrajudicialmente até os 16 (dezesseis) anos, nos atos da vida civil, e assisti-los, após essa idade, nos atos em que forem partes, suprindo-lhes o consentimento; (Redação dada pela Lei $n^{\circ} 13.058$, de 2014)

VIII - reclamá-los de quem ilegalmente os detenha; (Incluído pela Lei no 13.058, de 2014).

E no que diz respeito, ao exercício do poder familiar relativo ao usufruto e administração dos bens dos filhos menores (art. 1689 CC/02)?

Na hipótese de um conflito de interesses entre os pais, em situações comezinhas: escolha da escola, orientação religiosa, modalidade esportiva, tipo de alimentação. No tocante às datas e festas comemorativas (aniversário do filho, dia das mães, dia dos pais, Natal, Réveillon, entre outras), como assegurar uma distribuição equitativa de tempo entre os pais afetivos e biológicos. Há algum tipo de primazia, entre os vínculos? Será utilizado o critério do primeiro vínculo parental estabelecido? Por outro lado, esta opção não colide com o reconhecimento jurídico da igualdade entre os vínculos?

$\mathrm{Na}$ hipótese de guarda compartilhada e multiparentalidade. Como viabilizar na prática a guarda compartilhada na multiparentalidade e assegurar que a regra que "o tempo de convívio com os filhos deve ser dividido de forma equilibrada, com a mãe e com o pai" (CC/02 art. $1.583 \S$ 2). E o tempo de convivência com os avôs? Imaginando-se uma configuração familiar estabelecida entre uma mãe e dois pais, em princípio serão seis avôs, com iguais direitos a convivência. (Lei ${ }^{\circ}$ 12.398/2011).

Havendo a separação dos pais biológicos ou dos pais socioafetivos, ou de ambos os casais, como será o arranjo da convivência familiar ante a pluralidade de vínculos fragmentados? Se o número de litígios biparentais abarrotam às varas de família, imagine-se a potencialização de demandas judiciais, provenientes dos vínculos pluriparentais concorrentes.

Há de se ressaltar ainda, os problemas provenientes da pensão alimentícia. Como sabemos, diante da impossibilidade de um dos pais de pagar a dívida alimentar, o outro pai assumirá integralmente a dívida? Ou incide a regra que diante da impossibilidade do pai, a obrigação recairá no ascendente mais próximo, no caso o avô? Atentando-se para a orientação da Súmula 596 do STJ: "a obrigação alimentar dos avós tem natureza complementar e subsidiária, somente se configurando no caso da impossibilidade total ou parcial de seu cumprimento pelos pais".

Estas são apenas algumas hipóteses abordadas, mas há inúmeras outras possibilidades. E as regras do CC/02 apresentam respostas para dirimir estas demandas?

Pela gama de problemas, que podem advir no cotidiano da família multiparental, condicionamos a aplicação do instituto, se e somente se, estiver em conformidade com os princípios da proteção integral e do melhor interesse da criança.

Ratificando esta linha trazemos uma decisão recente da Terceira Turma do Superior Tribunal de Justiça (STJ). A ação, proposta em nome da filha menor, representada por sua mãe pretendia assegurar que a criança tivesse o pai socioafetivo e o pai biológico reconhecidos concomitantemente no registro civil.

A menina havia sido registrada pelo homem que vivia em união estável com a mãe, o qual, mesmo sem ter certeza da paternidade, optou por criá-la como filha e desejava continuar cuidando da menina.

No entanto, observou o relator, ministro Marco Aurélio Bellizze, que a ação foi movida por conveniência da mulher, exclusivamente, pois pretendia a retificação do registro para inclusão do pai biológico e criar com ele uma aproximação forçada. Ademais, o estudo social constatou, que o pai biológico não demonstrou nenhum interesse em registrar a filha ou em manter vínculos 


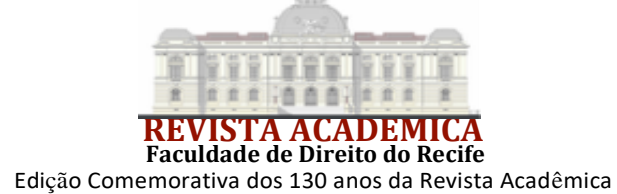

afetivos com ela. Circunstâncias determinantes para negar provimento ao recurso e afastar a multiparentalidade, com o seguinte destaque:

O melhor interesse da criança deve sempre ser a prioridade da família, do Estado e de toda a sociedade, devendo ser superada a regra de que a paternidade socioafetiva prevalece sobre a biológica, e vice-versa". A possibilidade de se estabelecer a concomitância das parentalidades socioafetiva e biológica não é uma regra, pelo contrário, a multiparentalidade é uma casuística, passível de conhecimento nas hipóteses em que as circunstâncias fáticas a justifiquem, o que não ficou demonstrado no processo e não é admissível que o Poder Judiciário compactue com uma pretensão contrária aos princípios da afetividade, da solidariedade e da parentalidade responsável.

O relator, por fim destaca:

a possibilidade do direito da filha, caso assim deseje, de buscar a inclusão da paternidade biológica em seu registro civil quando atingir a maioridade, tendo em vista que o estado de filiação configura direito personalíssimo, indisponível e imprescritível, que pode ser exercitado, portanto, sem nenhuma restrição, contra os pais ou seus herdeiros. ${ }^{7}$

\section{CONSIDERAÇÕES FINAIS}

Pelo exposto, os problemas decorrentes do cotidiano da multiparentalidade são inúmeros e as respostas continuam em aberto. Tal circunstância torna imperioso o estabelecimento de balizamentos concretos, a fim de nortear a aplicação da multiparentalidade de forma coerente e em observância com as regras postas no direito de família brasileiro. Razão pela qual defendemos que o critério binário da filiação continua sendo regra, a multiparentalidade deve se dar em caráter excepcional, dentro de parâmetros congruentes à realidade do caso concreto e ter como requisito a indissociável observância aos princípios da proteção integral e do melhor interesse da criança.

Consequentemente, a multiparentalidade deve ter um alcance restrito à filiação proveniente da posse de estado de filiação. O que afasta de plano a multiparentalidade na adoção, diante das regras estabelecidas no Estatuto da Criança e do Adolescente, quanto ao tema. Também não cabe a multiparentalidade, na filiação proveniente da utilização das técnicas de reprodução assistida heteróloga, onde é garantido o sigilo do doador $^{8}$ e incide a presunção de filiação, conforme estatuído no art. 1597,V do CC/02.

A multiparentalidade judicial imposta, destituída de um consenso entre todos os envolvidos pode representar uma violação ao princípio da não interferência na comunhão de vida instituída pela família ${ }^{9}$ e ao contrário do que se espera tornar-se fator potencializador de conflitos. Neste sentido para a viabilidade prática da multiparentalidade, deve-se adotar como regra a multiparentalidade judicial consensual ou multiparentalidade extrajudicial ${ }^{10}$, a depender do caso concreto.

Por fim, as palavras do Min. Edson Fachin, por ocasião do seu voto, quando afirmou que a efetiva viabilidade jurídica da multiparentalidade, só pode ser reconhecida quando se expressa na realidade da socioafetividade (o pai biológico quer ser pai, o pai socioafetivo não quer deixar de sê-lo, e isso atende ao melhor interesse da criança - ou é consentido pelo adolescente.

\section{REFERÊNCIAS}

BRASIL. CNJ. Provimento $n^{\circ}$ 83/2019.

BRASIL. STF. RE 898060. Disponível em: https://portal.stf.jus.br. Acesso em: 23 de nov. 2021.

7 Disponível em: http://www.stj.jus.br/sites/portalp/Paginas/Comunicacao/Noticias-antigas/2018/2018-04-25 07-

11 Reconhecimento-de-multiparentalidade-esta-condicionado-ao-interesse-da-crianca.aspx.

8 Conselho Federal de Medicina - Resolução no 2294/2021.

${ }^{9}$ CC/02. Art. 1513.

${ }^{10} \mathrm{CNJ}$ - Provimento $\mathrm{n}^{\mathrm{o}} 83 / 2019$ 
BRASIL. Supremo Tribunal de Justiça (3. Turma). REsp 1.674.849. Rel. Marco Aurélio Bellizze, 17 de abril de 2018. Disponível em:

www.stj.jus.br/sites/portalp/Paginas/Comunicacao/Noticias-antigas/2018/2018-04-25_0711 Reconhecimento-de-multiparentalidade-esta-condicionado-ao-interesse-da-crianca.aspx. Acesso em: 23 de nov. 2021.

BRASIL. Supremo Tribunal de Justiça (4. Turma). REsp 1.487.596-MG. Rel. Min. Antonio Carlos Ferreira, 28 de setembro de 2021. Disponível em: https://www.stj.jus.br. Acesso em: 23 de nov. 2021.

CONSELHO FEDERAL DE MEDICINA (Brasil). Resolução $n^{\circ}$ 2294/2021.

LOBO, Paulo. Estado de filiação e origem genética: uma distinção necessária. Disponível em: https://ibdfam.org.br/artigos/126/Direito+ao+estado+de+filia\%C3\%A7\%C3\%A3o+e+direito+\% C3\%A0+origem+gen\%C3\%A9tica:+uma+distin\%C3\%A7\%C3\%A3o+necess\%C3\%A1ria. Acesso em: 23 de nov. 2021

VILLELA. João Baptista. Desbiologização da paternidade. Disponível em: revista.direito.ufmg.br/index.php/revista/issue/view/62. Acesso em: 23 de nov. 2021. 